\title{
EDITORIAL
}

\section{Reversing concepts on COPD irreversibility}

\author{
J.B. Soriano**\# and D.M. Mannino
}

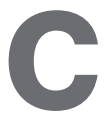

ommon diseases are complex. The study of complexity is based on a new way of thinking that stands in sharp contrast to the philosophy underlying Newtonian science, which is based on reductionism, determinism and objective knowledge. Initially, we might aim to reduce complexity to understand nature [1].

In the current issue of the European Respiratory Journal (ERJ), TASHKIN et al. [2] report the baseline results for bronchial hyperresponsiveness in patients recruited in an ongoing, large chronic obstructive pulmonary disease (COPD) clinical trial, the Understanding the Potential Long-Term Impacts on Function with Tiotropium (UPLIFT) trial [3]. This report [2] challenges the vastly established concept that lung function in COPD is largely irreversible. TASHKIN et al. [2] concluded that over one-half to nearly two-thirds of participating subjects met the most commonly used criteria for acute bronchodilator responsiveness, and more than one-third showed acute responsiveness by an increase in the percentage predicted criterion. Most certainly, the combined strategy employed in the UPLIFT trial involving the use of two bronchodilators (80 $\mu \mathrm{g}$ ipratropium and $400 \mu \mathrm{g}$ salbutamol) to ensure maximum or near-maximum bronchodilation magnifies this biological finding.

Currently, both American Thoracic Society/European Respiratory Society [4] and Global Initiative for Chronic Obstructive Lung Disease [5] COPD guidelines insist that COPD staging is to be performed post-bronchodilation; a previous recommendation of $400 \mu \mathrm{g}$ salbutamol [6] seems long forgotten. Both updated documents are vague in recommending what method, dose or treatment to follow. Not surprisingly, the most current asthma guidelines are also vague in recommending which, when and how a bronchodilator test should be administered (200-400 mg salbutamol to produce an increase in forced expiratory volume in one second (FEV1) of $>12 \%$ and $200 \mathrm{~mL}$ from the pre-bronchodilator value, no time specified) [7]. Additionally, to complicate matters further, one could add "corticosteroid reversibility" to the mix. Aiming high and because "the sky is the limit", some might aim to obtain reference equations of lung function in a super-healthy,

*Programme of Epidemiology and Clinical Research, CIMERA, Bunyola, and ${ }^{\#}$ CIBER Enfermedades Respiratorias, Spain. "Dept of Preventive Medicine and Environmental Health, University of Kentucky College of Public Health, Lexington, KY, USA.

STATEMENT OF INTEREST: Statements of interest for both authors can be found at www.erj.ersjournals.com/misc/statements.shtml

CORRESPONDENCE: J.B. Soriano, Programme of Epidemiology and Clinical Research, CIMERA Recinte Hospital Joan March, Carretera Soller Km 12, 07110 Bunyola, Spain. Fax: 34971148442. E-mail: jbsoriano@caubet-cimera.es nonsymptomatic, never-smoker sample of participants from the general population who are all bronchodilated with a combination of salbutamol, ipratropium and even an inhaled or oral corticosteroid. We don't think this should be the case.

The issue of definitions of reversibility of lung function in COPD has been visited in the ERJ [8,9] and elsewhere before. It is probable that the resources required, should the pattern of bronchodilation used in the UPLIFT trial [3] be implemented in other trials, population studies and clinical practice, might be untenable, and may not even be important, as time $(2 \mathrm{~h}$ minimum) and estimated costs might be considered impractical in many settings. Post-bronchodilation spirometric values are considered more valid than pre-bronchodilator values, but safety also needs to be considered. Paradoxical bronchospasm after administration of a bronchodilator is an infrequent event. A decrease in FEV1 of $>12 \%$ and $200 \mathrm{~mL}$ occurred in only $0.24 \%$ of the participants in the UPLIFT trial [3]. However, fatal or near-fatal events are described elsewhere [10], usually raising safety concerns in ethics committees whenever protocols that require post-bronchodilator spirometry are assessed. In contrast, the usefulness of the simplest spirometry pre-bronchodilator manouvre, vital capacity, to predict long-term total and cardiovascular mortality even better than cholesterol, blood pressure or other biomarkers, has long been established [11].

Another recent, large, well-conducted COPD trial [12] used a different bronchodilation method and threshold, an increase in FEV 1 of $<10 \%$ of the predicted value with the use of $400 \mu \mathrm{g}$ salbutamol. No significant effects in all major end-points according to the degree of reversibility were reported. It will be of interest to observe whether this is sustained in UPLIFT [3]. Should there be no effect modification both in efficacy and safety in COPD treatments, a call for not stratifying clinically diagnosed COPD patients by reversibility should be made. If the broncholidation method is not standardised as previously discussed, why do guidelines call for post-bronchodilator values to assess COPD severity and irreversibility if treatments work equally well across all levels of reversibility?

From a public health point of view, a related, relevant issue in respiratory medicine is perhaps that current views of reversibility misclassify large segments of the population [13], resulting in a significant portion of asthmatic sufferers (smokers and the elderly) and COPD sufferers (subjects with a positive bronchodilator test) being excluded from clinical trials. Therefore, their respective treatment is not evidence-based.

A more important question, however, may be the extent to which, and the ways in which, reversibility is actually important in COPD. In a classic study of $>1,000$ asthma patients (many of whom would meet current case definitions for COPD), ULRIK 
and FREDERIKSEN [14] found that increasing degrees of reversibility predicted a higher risk of death during follow-up. This can be contrasted with results from another study by HANSEN et al. [15], who found that the degree of reversibility (from the baseline lung function measurement) was protective against mortality and that the best attainable FEV1 was the best predictor of mortality. The world of COPD and medicine, however, has changed a great deal since these studies $[14,15]$ were carried out. We now acknowledge the large overlap between asthma and COPD and the importance of comorbid diseases in our patients. It is in this light that we may need to revisit concepts of reversibility, i.e. if achieving maximal bronchodilation adversely affects the cardiovascular system, attaining this maximum lung function may actually harm the patient.

This is a call for simplicity. Striking a balance between reductionist and whole-systems thinking is a lifelong ambition, and challenging existing recommendations with an end to its fine clinical application is a reasonable path [16]. Any classification recommended by guidelines is intended to be applicable to populations and not to substitute clinical judgment in the evaluation of the severity of disease in individual patients. Data, such as those provided by TASHKIN et al. [2], should help revisit, once more, the issue of chronic obstructive pulmonary disease definitions.

\section{REFERENCES}

1 Waldrop MM. Complexity: The Emerging Science at the Edge of Order and Chaos. London, Viking, 1992.

2 Tashkin DP, Celli B, Decramer M, et al. Bronchodilator responsiveness in patients with COPD. Eur Respir J 2008; 31: 742-750.

3 Decramer M, Celli B, Tashkin DP, et al. Clinical trial design considerations in assessing long-term functional impacts of tiotropium in COPD: the UPLIFT trial. COPD 2004; 1 : 303-312.

4 Celli BR, MacNee W, ATS/ERS Task Force. Standards for the diagnosis and treatment of patients with COPD: a summary of the ATS/ERS position paper. Eur Respir J 2004; 23: 932-946.

5 Rabe KF, Hurd S, Anzueto A, et al. Global strategy for the diagnosis, management, and prevention of chronic obstructive pulmonary disease: GOLD executive summary. Am J Respir Crit Care Med 2007; 176: 532-555.

6 Pauwels RA, Buist AS, Ma P, Jenkins CR, Hurd SS, GOLD Scientific Committee. Global strategy for the diagnosis, management, and prevention of chronic obstructive pulmonary disease: National Heart, Lung, and Blood Institute and World Health Organization Global Initiative for Chronic Obstructive Lung Disease (GOLD): executive summary. Respir Care 2001; 46: 798-825.

7 Bateman ED, Hurd SS, Barnes PJ, et al. Global strategy for asthma management and prevention: GINA executive summary. Eur Respir J 2008; 31: 143-178.

8 Sterk PJ. Let's not forget: the GOLD criteria for COPD are based on post-bronchodilator FEV1. Eur Respir J 2004; 23: 497-498.

9 Mannino DM. Defining chronic obstructive pulmonary disease... and the elephant in the room. Eur Respir J 2007; 30: 189-190.

10 Cocchetto DM, Sykes RS, Spector S. Paradoxical bronchospasm after use of inhalation aerosols: a review of the literature. J Asthma 1991; 28: 49-53.

11 Ashley F, Kannel WB, Sorlie PD, Masson R. Pulmonary function: relation to aging, cigarette habit, and mortality. Ann Intern Med 1975; 82: 739-745.

12 Calverley PM, Anderson JA, Celli B, et al. Salmeterol and fluticasone propionate and survival in chronic obstructive pulmonary disease. N Engl J Med 2007; 356: 775-789.

13 Soriano JB, Davis KJ, Coleman B, Visick G, Mannino D, Pride NB. The proportional Venn diagram of obstructive lung disease: two approximations from the United States and the United Kingdom. Chest 2003; 124: 474-481.

14 Ulrik CS, Frederiksen J. Mortality and markers of risk of asthma death among 1,075 outpatients with asthma. Chest 1995; 108: 10-15.

15 Hansen EF, Phanareth K, Laursen LC, Kok-Jensen A, Dirksen A. Reversible and irreversible airflow obstruction as predictor of overall mortality in asthma and chronic obstructive pulmonary disease. Am J Respir Crit Care Med 1999; 159: 1267-1271.

16 Sturmberg JP. Systems and complexity thinking in general practice: part 1 - clinical application. Aust Fam Physician 2007; 36: 170-173. 